THURSDAY, NOVEMBER 30, I882

\section{THE INDIAN SURVEY}

General Report on the Operations of the Survey of India during 1880-8I. 6I pp. Report, 93 pp. Appendix, and 22 Plates. (Calcutta, I 882.)

THIS Report for $1880-8 \mathrm{r}$ (the fourth since the various branches of the Indian Survey were amalgamated) shows as usual a good amount of useful work done in the year, and contains also many points of general interest. There were in all twenty-nine field-parties and six large head-quarters' offices. The whole out-turn of work cannot be shortly stated, and the total cost is not given; but it appears that there were 22,765 square miles surveyed topographically, 6I4I square miles in great detail, besides much minor and special work, also that eleven Revenue Branch parties surveyed II,326 square miles at a cost of about $8 \mathrm{r}, 000 \mathrm{l}$.

The principal triangulation of India proper as designed by Col. Everest, has now been finished. The result is shown on a skeleton map, which is itself a wonderful sight. There is a continuous "chain " of triangles right round India proper, connected across by many meridional and east to west "chains," the longest being from Mussoorie to Cape Comorin (say I60o miles north to south), and from Chittagong to Kurrachee (say I800 miles east to west). Outside India proper there are five important extensions, viz. (I) to Kandahar and Khelat; (2) over Káshmír ; (3) up the Indus beyond Leh ; (4) up the Brahmaputra to Sudya ; and (5) a coast "chain" from Chittagong to Tenasserim. This great work, now finished, is one of which India may well be proud.

Certain important changes of procedure are being introduced in the general survey work, viz.: (I) All the topographical work is being brought to a uniform system; (2) Fieldbooks are gradually giving way to direct plotting of detail in the field with advantage in speed of work and economy; (3) Special riverain surveys will in future be made; (4) Local agency is being tried for detail work; this last measure is expected to effect great economy in the survey of Burma, for which at present a staff of 2500 men is taken from Calcutta and back again each season.

Great difficulties often beset the parties in the wilder parts of the country. Many parts are extremely unhealthy, and the parties often suffer severely from fever, \&c. In a few parts the roughness of the country, in others climatic conditions, render travelling exceptionally difficult, e.g. travelling in the hot wind across the "Rann" (great sait desert) of Katch is dangerous to both man and beast. In a few parts even in India proper, e.g. among the wild Bhils, the surveyors are looked on with suspicion and sometimes attacked. The greatest praise is due to men who carry out their fieldwork through such difficulties as these.

In general a survey party now accompanies every military expedition; thus some extension of geographical and trigonometrical work was done in I88r by parties sent with the Mahsúd Wazír expedition and with the troops at Kandahár. A curious difficulty has arisen in that the modern use of the heliostat in military signalling almost precludes its use for survey stations along with an army.

VOL. XXVII.-No. 683
Self-registering tide-gauges with 5 feet barrels have been set up at fourteen places, and have worked well as a whole. Tide registrations (mostly from older instruments) for twenty-three years in all have been analysed by the harmonic analysis at enormous labour. The discussion shows (for the first time) the existence of a "lunar fortnightly tide" as had been expected from the tidal theory. Tide-tables for $\mathrm{J} 882$ were published for fifteen ports.

The tidal stations of Madras and Bombay have been connected by "levelling" right across the peninsula with the curious result that the mean sea-level at Madras appears to be 3 feet above that of Bombay. The cause of this is still a subject of inquiry. It is really a very curious question. Thus, it is said that "there can be no sensible differences of level," i.e. as determined by levelling, "because the causes by which they would be produced must equally affect the spirit-levels of the instruments and the water-levels of the ocean," so that had the "levels been carried, without error, along the coast line from Bombay . . . to Madras, they must have shown identity of sea-level, \&cc." On the other hand it is also said that "the Western Ghats are a source of attraction, which, if not counteracted, must raise the sea-level at Bombay no less than 3I feet above the mean sea-level at Madras." The difference (which should be zero?) is attributed to observation-error, and chiefly to the effect of the oblique sunlight illuminating the two ends of the instrument-bubble unequally: thus it is said that an error of only $\mathrm{I} \cdot 2$ seconds in levelment (a very minute quantity) at even one-fourth of the instrumental stations would produce the total error in question.

An interesting improvement has been introduced in the engraving branch, viz. in steel-facing the copper-plates, and is said to be very successful. Apparently engraving on copper is still largely used (as also in the British Ordnance Survey), but it would seem that this tedious and costly process must give way to some of the rapid and cheap photographic processes. The Indian Survey is also utilising the latter very largely, with the wonderful result that "at present publication may, and frequently does, follow the survey in a few days." There is a curious instance of the possible saving in deparmental manufacture, in that about $334 l$. has been saved by making up collodion in the office instead of purchasing it.

Of underground temperatures it is noted that at Dehra the maxima occurred at the three depths, $6.4,12 \cdot 8,25 \cdot 6$ feet, about September 20, October 15, and November 15 respectively (the maximum in the air being probably in June ?).

An extraordinary outburst of solar spots, covering 630 million square miles, was observed to take place on July 25 , I88I, within a period of thirty-seven minutes; it is rare that so grand an outburst is so closely located in time.

The Indian Survey was well represented at the Venice Geographical Exhibition. The whole collection sent seems to have excited great interest, especially the tidal instruments which were connected with the Main Canal so as to be shown in actual work. This exhibition brought to light a striking difference in recent practice of construction of instruments in England and on the Continent in that recent improvements in graduating circles are so 
great as to lead to the general adoption (by continental makers) of small circles with powerful reading micrometers in place of large circles with verniers.

A very simple process of making relief maps in Germany is described, viz. by cutting out contour strips from a contoured map, and pasting each on to cardboard cut to same outline. Altogether the Report is a very interesting one.

Allan Cunningham

\section{GREEN'S "GEOLOGY"}

Geology. By A. H. Green. Part I. Physical Geology. Third and Enlarged Edition. (London: Rivingtons, I882.)

GTUDENTS of Geology will welcome this third and D much enlarged edition of Prof. Green's excellent text-book, though they may at first sight regret the exchange of the old convenient manual form of the book for that of the present handsome and well-printed octavo. One of the first features that strikes the reader in this new issue of the work is the large augmentations made to the lithological sections. In fact this part of the treatise mily be said to have been re-cast and almost wholly re-written. The author devotes I 50 closely printed pages to crystallography and the description of minerals. It may be open to question whether the full details which he gives to the crystallographic characters of minerals are not rather out of place in a geological treatise. They are not ample enough for the mineralogical student, and the geologist who takes up the subject must necessarily study text-books of mineralogy, where they are given at much greater length. Prof. Green, however, has put them so clearly and succinctly that this portion of his book cannot fail to be of use.

Some changes have been made in the arrangement of rocks. The non-crystalline or derivative rocks now come first-a grouping which no doubt has its advantages in teaching, particularly in elementary classes, but which is not that usually employed in petrographical works. After briefly describing the lithological character of the noncrystalline rocks, the author, following his original plan, proceeds to discuss the mode of formation of these rocks, dealing first with denuding agents and their work, and then considering the manner in which the denuded material is aggregated into rock-masses. In these sections he brings his subject abreast of the onward march of the science. Another change in the original treatment of his subject occurs in the author's chapter on the "confusedly crystalline rocks." He has not been so happy in his choice of a title for them as he has been in his description of their general characters. After giving an account of the lithological features he proceeds to discuss their modes of origin, dealing first with volcanoes recent and extinct, then with eartbquakes (though one wonders what these have to do with a description of crystalline rocks), next with plutonic rocks which, however, are rather inadequately discussed. The chapter on metamorphic rocks has been carefully revised, and may be commended to the student as an admirable summary of what is at present known on this subject. The chapter upon the way in which rocks came into their present positions was one of the best in the first edition of the book. Its excellence has now been increased by a thorough revision. For practical insight into the structure of the earth's crust it is unsurpassed in any treatise known to us.

Prof. Green more than makes up for the curious omission in the first edition of any mention of mineral veins. We doubt, however, the advantage of inserting minute descriptions of metallic ores in a general geological textbook. The author would do well in his next edition to give references to the Continental works on mining, particularly to some of the numerous treatises which have been published in Germany. Chapter XIII. retains its place as a valuable account of how the present surface of the ground has been produced. The last two chapters discuss the former fluidity and present condition of the earth's interior, the cause of upheaval, contortion, and metamorphism, and the origin of the changes of climate which have taken place during geological time. These parts of the book are exceedingly well done. The author has held the balance fairly between contending disputants, and sums up the evidence with conspicuous and judicial impartiality. Altogether, he may be congratulated on the appearance of this edition of his text-book, which sustains and extends his reputation as an exponent of his favourite science.

\section{OUR BOOK SHELF}

$A$ History of British Birds. By the late William Yarrell. Fourth Edition, Revised to the end of the Wryneck, by Alfred Newton, M.A., F.R.S., continued by Howard Saunders, F.L.S., F.Z.S. Part XV. (London: John Van Voorst, November, 1882.)

THE fifteenth part of the new edition of what the British ornithologist fondly calls his "Yarrell" contains the final contribution of Prof. Newton to this work, and the first pages of the portion which Mr. Howard Saunders, his successor in the editorship, has undertaken. Few of the subscribers, we believe, will be much pleased with the change of authorship of their favourite work of reference. No living writer, it may be confidently asserted, is so competent to prepare a new edition of "Yarrell's British Birds" as Prof. Newton, and the conscientious care with which he has laboured upon the two volumes now completed must be patent to all who consult them. At the same time it should not be forgotten that time is an element in all human matters not even excepting books on British birds. When, therefore it is considered that nearly eleven years have elapsed since Prof. Newton commenced his new edition, and that only the first half of the work is now completed, it is obvious that the Professor has not acted unwisely in surrendering the second half to an editor who is able to devote more time to the undertaking.

Mr. Howard Saunders, it is generally understood, intends to issue the two final volumes of the new edition in two years, and if his health and strength permit, will doubtless accomplish his task within the allotted period. In this his large practical knowledge of the bird-life of Southern Europe, as well as his well-known familiarity with modern ornithological literature, are likely to be of the greatest assistance.

Mr. Saunders commences his second volume with the pigeons, and gives us an excellent account of the four British species, as also of the American passenger pigeon, which can only be looked upon as one of our rarest stragglers from the New World. When, however, he says that all true pigeons lay two eggs he must have forgotten that the crowned pigeons, and the numerous forms of fruit-pigeons are, so far as is known, content to lay but one. There is therefore no good reason for calling the 